FORMATION Formation emploi

Revue française de sciences sociales

119 | juillet-septembre 2012

pêle-mêle

\title{
La professionnalisation dans un environnement mosaïque
}

Jean-Frédéric Vergnies

\section{(2) OpenEdition}

\section{Journals}

Édition électronique

URL : http://journals.openedition.org/formationemploi/3675

DOI : 10.4000/formationemploi.3675

ISSN : 2107-0946

Éditeur

La Documentation française

Édition imprimée

Date de publication : 10 septembre 2012

ISSN : 0759-6340

\section{Référence électronique}

Jean-Frédéric Vergnies, « La professionnalisation dans un environnement mosaïque », Formation emploi [En ligne], 119 | juillet-septembre 2012, mis en ligne le 26 octobre 2012, consulté le 30 octobre 2020. URL : http://journals.openedition.org/formationemploi/3675; DOI : https://doi.org/10.4000/ formationemploi.3675

\section{(c) Tous droits réservés}




\title{
La professionnalisation dans un environnement mosaïque
}

\author{
Jean-Frédéric Vergnies
}

Rédacteur en chef

'intégration des jeunes dans l'emploi est un défi essentiel de la société française. Qu'est-
nous qui contribue à faire d'un jeune un bon professionnel ? Les articles de ce numéro
portance de l'environnement où ils prennent place.

S. Oudet développe la notion d'environnement capacitant en se fondant sur l'approche par les capacités, à la suite d'A. Sen. Un environnement capacitant participe " au développement de ces dispositions à apprendre, sans lesquelles il est difficile de penser quiun individu puisse s'engager dans des situations d'apprentissages». Les approches, notamment de formation, focalisées sur les tâches, montrent ici leurs limites et invitent à considérer de manière large les activités et les conditions d'exercice de l'emploi ou du poste de travail. Ici, S. Oudet montre comment des formations professionnelles au sein d'une grande entreprise deviennent véritablement opérationnelles lorsqu'elles sont adossées à un réseau, comme ici l'expérience originale d'un réseau réciproque d'échanges des savoirs (RERS). Ce réseau est d'autant plus professionnalisant qu'il est soutenu par l'organisation, la hiérarchie et l'encadrement de proximité.

Les contraintes économiques de l'entreprise, et notamment le type de relation avec les clients ou donneurs d'ordres constituent un autre élément important de l'environnement. A. Dietrich et F. Lozier soulignent le rôle des stratégies en matière de ressources humaines, loin de tout déterminisme simplificateur. En effet, le type de prestation de service (régie/ forfait) ne détermine pas automatiquement les modalités d'emploi (précaire/stable). Certaines sociétés de services en ingénierie informatique (SSII) privilégient délibérément la diversité parmi leurs collaborateurs. Ainsi, elles ne recrutent pas prioritairement des jeunes ingénieurs en informatique, et le maillage de cette diversité de profils en termes de niveaux de diplômes, de domaines de compétences ou de champs d'expérience favorise l'intégration durable des plus jeunes tout en étant fécond pour l'entreprise. 
Pour sa part, F. Aubry nous rappelle le rôle des pairs dans l'intégration professionnelle. En comparant l'intégration professionnelle des jeunes aides-soignantes au Québec et en France, il souligne combien le recrutement et l'intégration des jeunes sont portés par des normes et des stratégies collectives, que Y. Clot qualifie de " genre professionnel ».

On peut aussi s'interroger de manière plus large sur la conception de la qualification et du métier portée par l'environnement. S. Proust s'intéresse ici à un dispositif de professionnalisation dans une profession très atypique : les comédiens, avec l'instauration d'un contrat de professionnalisation géré par un groupement d'employeurs. Il révèle comment la conception même du métier pour les différents protagonistes (metteurs en scène, directeur artistique, comédiens...) peut invalider au final un dispositif de formation professionnelle destiné à développer les qualifications et les compétences des comédiens.

Pour clore ce numéro, en analysant le champ du travail social, M. Hatano réaffirme que la représentation des métiers, des cultures professionnelles et des identités sociales repose en partie sur la formation et son organisation. Ainsi, une nouvelle forme d'organisation des formations, comme l'individualisation des parcours, peut avoir des conséquences ambivalentes. D'une part, elle permet d'instaurer de nouveaux formats pédagogiques, flexibles, modulables, facilement accessibles, qui développent des compétences juxtaposées et liées à des situations professionnelles plutôt qu'à une posture professionnelle, tout en étant adaptés aux contraintes des employeurs. De l'autre, certaines formations privilégient un ensemble d'activités et l'apprentissage d'une culture de métier, elles sont alors moins accessibles et peu propices à l'individualisation des parcours ; l'approche individualisée ne saurait être ici appliquée au risque de perdre la cohérence des cœurs de métier. Au final, il apparaît qu'un environnement professionnel est également soumis à des réformes successives et par conséquent est rendu instable et imprévisible ; l'harmonisation des pratiques pédagogiques constitue alors d'autant plus un enjeu majeur des politiques et dispositifs de formation.

Bonne lecture à tous. 